\title{
|ANALYSIS OF WORKFLOW ON DESIGN PROJECTS
IN INDIA
}

doi> $10.4237 / g t p . v 5 i 3.176$

\author{
Senthilkumar VENKATACHALAM \\ Senior Project Officer, IIT Madras, India \\ |e-mail: vsenthil@iitm.ac.in| \\ Koshy VARGHESE, \\ Professor, IIT Madras, India \\ |e-mail: koshy@iitm.ac.in|
}

\begin{abstract}
Proposal: The increase in privately funded infrastructure construction in India had compelled project owners to demand highly compressed project schedules due to political risks and early revenue generation. As a result, many of the contracts are based on EPC (Engineering Procurement and Construction) contract enabling the contractor to plan and control the EPC phases. Sole responsibility for the three phases has facilitated the use of innovative approaches such as fast-track construction and concurrent engineering in order to minimize project duration.

As a part of a research study to improve design processes, the first author spent a year as an observer in two design projects which was done by a leading EPC contractor in India. Both projects required accelerated design and fast-track construction. The first project involved the detailed design of a coal handling unit for a power plant and second the preliminary phase of a large airport design project. The research team had the mandate to analyze the design process and suggest changes to make it more efficient.

On the first project, detailed data on the design/ drawing workflow was collected and analyzed. The paper presents the analysis of the data identifying the bottlenecks in the process and compares the analysis results with the perceptions of the design team. On the second project, the overall organizational structure for coordinating the interfaces between the design processes was eval uated. The paper presents a structured method to organize the interface and interactions between the various design disciplines. The details of the method proposed, implementation issues and outcomes of implementation are also discussed.
\end{abstract}

Keyw ords: Design Management, Interface Management, Design Delay A nalysis. 


\section{I NTRODUCTI ON}

India has been experiencing a higher growth in GDP over the last few years. To sustain this growth, investments in infrastructure development of about US \$320 billion have to be made over the next five years (Parekh 2007). Most of these investments are based on the Public Private Partnership (PPP) model, as political risks in PPP projects are high, it is vital that the projects are completed and commissioned in the shortest possible duration. Further, a compressed duration also enables early generation of revenue which enhances the profitability of the venture.

The need to compress project schedules has put pressure on traditional contracting and construction practices. At present, the EPC contracts have become a popular approach. Having total responsibility of EPC phases has facilitated many contractors to accelerate the project schedule by adopting concurrent engineering and fast-track techniques in design and construction. While the acceleration of the construction phase (independently) has been a common demand in the past and localized techniques to achieve this are available, the acceleration of design/ engineering phase and the coordination of the EPC interfaces have been a challenge.

The key challenge arises from the facts that, design has a numerous of interdependent, knowledge intensive multidisciplinary tasks and the overall process is inherently iterative in nature. Thus managing this phase requires careful planning and coordination of the information exchange between the disciplines. Concepts and techniques to manage design information are the new area of research and with little formalization of practices. (Eppinger 1994, Austin 1996).

This paper is based on a study of design practices on two projects. The first project, Coal handling unit design was in the detailed design stage and the study focused on determining and analyzing the reasons for delay in design deliverables based on the records and the expert interview. The lessons learnt from the first case study were critically analyzed and an improved methodology was proposed to avoid delay and revisions in the second case study Airport design. The proposed methodology is adopted in the second case study from its conceptual stage of design phase. The implications and the difficulties during the proposed 
methodology were captured and the suitable suggestion has been made for the improvement.

The first case-study which involves the study of drawing submission and approval delays for the design of a coal handling unit is presented and analyzed critically for its causes in the next section. The subsequent sections investigate the existing organizational structure and it's suitability towards the application of the proposed methodology in the second case study. The final section presents implementation issues along with the discussion on the findings from the studies and potential for improvements.

\section{CASE STUDY 1: COAL HANDLI NG UNIT DESI GN}

The coal handling system of a thermal power plant cleans and supplies coal to the fuel chamber. The design involves components such as, Transfer points, Trackhopper, Conveyer, Crusher house, Stacker \& Reclaimer etc. Each discipline involved in the design process released drawings as their design output. These drawings were sent to the approval authorities for checking. At the time of study, detailed design was underway and the EPC firm was under pressure, since there were significant delays in their drawing release.

The key objectives of documenting this case were to quantify the delay, to assess root causes for the delay and to give suggestions for the improved solution process in the forthcoming projects. Before the analysis starts, the designers and design leaders were asked to list out the reasons for their drawing delays. The unique answer from them was; the delays were due to the approval authorities. To check the validity of the above statement, the author decided to analyze the drawing submission process through existing design documents. Data for assessment was collected in two phases. In the initial phase, data compiled as a part of the Drawing Control Index (DCI) was collected. In the next phase, designers were interviewed to discuss potential specific causes for each delay.

The $\mathrm{DCl}$ consists of information on the scheduled submission, actual submission and approved dates of each drawing with their revision numbers. There are many reasons for the drawings to be delayed. But a drawing is considered to be delayed only due to design process, if sufficient recourses are available. As the design team 
has adequate resources for this project, all delays are classified as design delays. The drawings got revised only when the drawing is non- confirmed to the client's functional or technical specifications.

Five measures are developed to validate the designer's opinion of drawing delay causes from the $\mathrm{DCl}$, these are as follows:

1. No of Revisions $=$ Number of time the drawing is submitted to the approval authorities

2. Delay in First Submission (days) $=$ Actual $1^{\text {st }}$ Submission Date - Schedule $1^{\text {st }}$ Submission Date

3. Delay in First Approval $=1^{\text {st }}$ Approval Date $-1^{\text {st }}$ Submission Date -15 . (15 is the approval duration mentioned in the contract agreement)

4. Total Delays due to Revisions $=$ Last A pproval Date $-1^{\text {st }}$ Approval Date

5. Total Delay except App $=$ Last Submission Date $-1^{\text {st }}$ Submi ssion Date - Total

$$
\text { Approval Days }+15
$$

(Total delay purely due to submission authorities)

A total of 700 drawings were scheduled for the coal handling design plant. Since the $\mathrm{DCl}$ records were not maintained in an appropriate format for statistical analysis, only the mechanical system drawings (total of 46 numbers) were taken as the sample for the initial analysis. The statistical results of the analysis (for a sample of 46 drawings) are as shown in Table 1.

\begin{tabular}{|c|c|c|c|c|c|}
\hline Sample size = 46 & $\begin{array}{c}\text { No of } \\
\text { Revisions } \\
\text { (No) }\end{array}$ & $\begin{array}{c}\text { Delay in } \\
\text { First } \\
\text { Submissi } \\
\text { on } \\
\text { (Days) }\end{array}$ & $\begin{array}{c}\text { Delay in } \\
\text { First } \\
\text { Approva } \\
\text { I } \\
\text { (Days) }\end{array}$ & $\begin{array}{c}\text { Total } \\
\text { Delays } \\
\text { Due to } \\
\text { Revisions } \\
\text { (Days) }\end{array}$ & $\begin{array}{c}\text { Total } \\
\text { Delay } \\
\text { Except } \\
\text { A pprova } \\
\text { I } \\
\text { (Days) }\end{array}$ \\
\hline Mean & 1.2 & 15.9 & 5.7 & 77.6 & 62.6 \\
\hline
\end{tabular}




\begin{tabular}{|l|c|c|c|c|c|}
\hline Std. Deviation & .94 & 35.5 & 8.8 & 71.8 & 75.3 \\
\hline Minimum & .00 & .00 & .00 & .00 & .00 \\
\hline M aximum & 4.00 & 141.00 & 39.00 & 283.0 & 258.0 \\
\hline
\end{tabular}

The above table shows the results from SPSS for all the above said measures. It can be seen from the table that for the sample of 46 drawings, there has been a maximum of four revisions and the mean number of revisions is 1.2. The histogram in figure 1 shows the distribution of the sample and it can be seen that most drawings underwent revisions. Similarly there are delays in first submission apart from the approval delay.

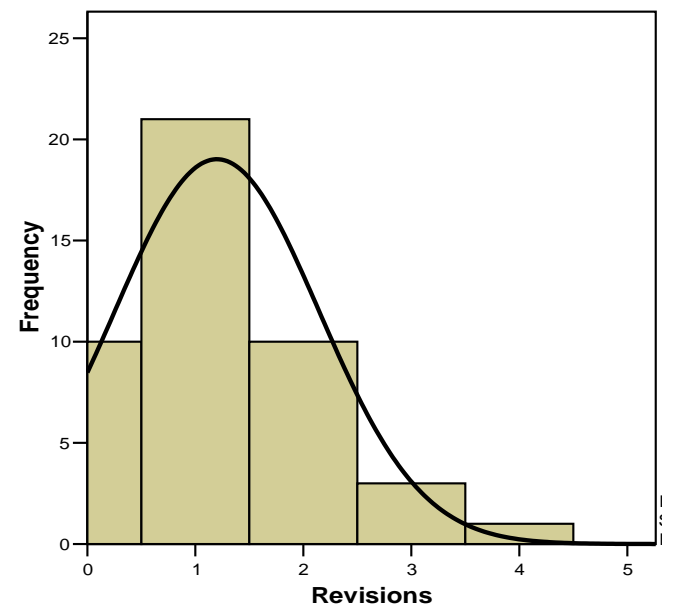

Figure 1 Histogram shows the number of revisions and the drawing frequency

Although the sample statistics(from table 1) suggest that the average submission delay of 15.9 days is much larger than the average approval delay of 5.7 days, the comparison of the categorized delay analysis is shown in figure 2 . From this, it is clear that there are almost equal numbers of submission delay apart from the approval delay. The pie chart shows that there are 4 drawings got 'both approval and submission delay', 18 drawings got 'only approval delay' and 12 drawing got 'only submission delay' and 12 drawings are 'not delayed'. The difference in the average value of submission and approval delay in table 1 is due to a few drawings which are inordinately delayed at submission stage. 

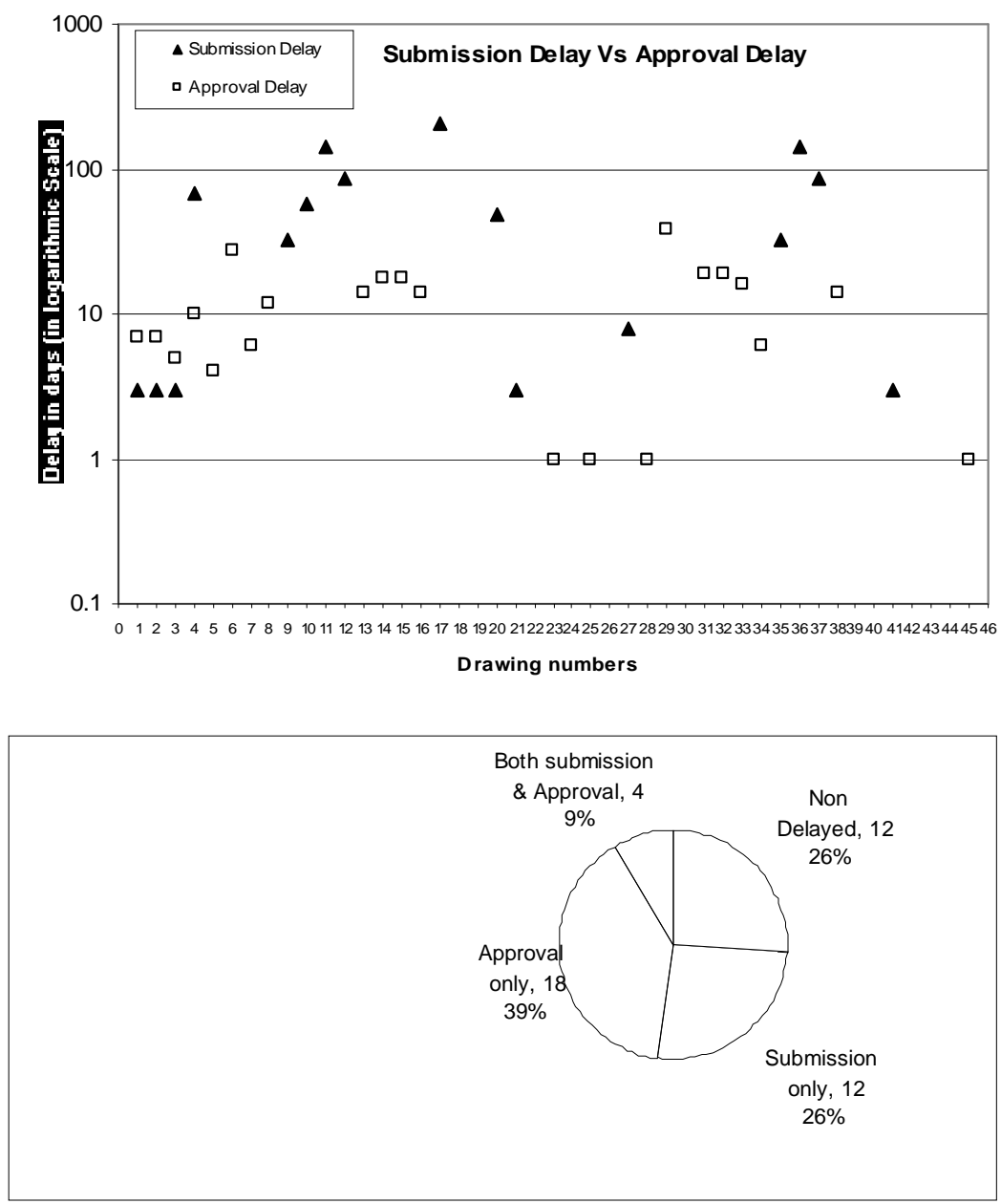

Figure 2 Comparison between the approval delay and submission delay

A part from this, the drawings got delayed because of its revisions, there are many reasons for the drawings to be get revised (A rain et al. 2006). From table 1, 'the average total delays' due to revisions are 77.6 days. And the 'average delays due to submission authority alone', that is 'the total delay except approval' is 66.2 days. It is clearly evident that the delay contributions from the submission side (designers) are considerable when compared to the delay contributed by the approval. One cannot claim the total delay was purely due to the design team, there are many factors which might influence the designers to submit the faulty design and delayed submission. The next section analyzes the specific reason for each of the above said delay and the same is represented by a cause effect diagram.

\section{WORK FLOW ANALYSIS AND THE CAUSES OF THE DESIGN DELAY}

The root cause analysis starts with the work flow study of the process. The work flow of a coal handling unit design involves interaction between internal as well as 
the external designers, client and vendors/ subcontractors. In addition, regulatory agencies and the site conditions also influence the design process significantly. Based on feedback from the design team and literature (Arain et al., 2006), it was found that drawing revision/delay arises due to the non-conformance of the specific need from the client and other design needs of regulatory authorities.

The design team was interviewed and asked for the specific reasons of each delayed/revised drawing. From the analysis it was found that there were 545 drawings underwent revisions out of 711 drawings. The total number of drawings found for the first delayed submission was 372 . All the 372 drawings that were submitted with delay underwent revisions. Focused interviews were conducted for the revision or delay reasons with the designer concerned. The delay/ revision causes were listed into the following five categories. 1. Designer's error and omissions; 2. Differing site conditions; 3. Owner initiated changes 4. Vendor's error and omissions and 5. Changes in laws of regulatory agencies. Table 2 shows the frequency of each of the delay causes identified.

Based on Table 2, a cause and effect diagram is drawn and the same is shown in figure 3. Some of the causes can be solved through the preventive steps and better design management processes. Of the factors identified in table 2 and figure 3 , the bolded factors are influenced by interface management practices and collaborative design processes.

\begin{tabular}{|c|c|c|c|c|c|}
\hline $\begin{array}{l}\text { Sl } \\
\text { No }\end{array}$ & Category & Causes & $\begin{array}{l}\text { Frequenc } \\
y\end{array}$ & $\%$ & Rank \\
\hline 1 & \multirow{5}{*}{$\begin{array}{l}\text { Designer's } \\
\text { Error and } \\
\text { Omissions }\end{array}$} & Inappropriate Assumptions & 83 & 13.43 & 1 \\
\hline 2 & & Poor Information Flow & 73 & 11.81 & 3 \\
\hline 3 & & Lack of Human Resources & 2 & 0.32 & 24 \\
\hline 4 & & $\begin{array}{l}\text { Inappropriate Sequence of } \\
\text { Work Performed }\end{array}$ & 25 & 4.05 & 11 \\
\hline 5 & & Less Productivity & 1 & 0.16 & 25 \\
\hline
\end{tabular}




\begin{tabular}{|c|c|c|c|c|c|}
\hline 6 & & Ripple out Effect & 64 & 10.36 & 4 \\
\hline 7 & & $\begin{array}{l}\text { Optimistic Design Duration } \\
\text { Estimation }\end{array}$ & 12 & 1.94 & 15 \\
\hline 8 & & Design Error & 42 & 6.80 & 5 \\
\hline 9 & \multirow{6}{*}{$\begin{array}{l}\text { Vendor's } \\
\text { Error and } \\
\text { Omissions }\end{array}$} & Inefficient Vendor Data & 15 & 2.43 & 14 \\
\hline 10 & & Superseded Vendor Data & 2 & 0.32 & 22 \\
\hline 11 & & $\begin{array}{l}\text { Insufficient Information in } \\
\text { Vendor Data }\end{array}$ & 19 & 3.07 & 13 \\
\hline 12 & & $\begin{array}{l}\text { Missing Data in Vendor } \\
\text { Documents }\end{array}$ & 33 & 5.34 & 6 \\
\hline 13 & & Uncertain Vendor Data & 8 & 1.29 & 16 \\
\hline 14 & & Incorrect Vendor Data & 28 & 4.53 & 8 \\
\hline 15 & \multirow{4}{*}{$\begin{array}{l}\text { Differing } \\
\text { Site } \\
\text { Conditions }\end{array}$} & $\begin{array}{l}\text { Changes of Construction } \\
\text { Methods }\end{array}$ & 4 & 0.65 & 20 \\
\hline 16 & & Change of Soil Properties & 6 & 0.97 & 19 \\
\hline 17 & & Change of Loads & 21 & 3.40 & 12 \\
\hline 18 & & Other Unanticipated Reasons & 27 & 4.37 & 10 \\
\hline 19 & \multirow{4}{*}{$\begin{array}{l}\text { Owner } \\
\text { Initiated } \\
\text { Changes }\end{array}$} & Suspension of Work & 2 & 0.32 & 23 \\
\hline 20 & & Ambiguous Specification & 79 & 12.78 & 2 \\
\hline 21 & & Change of Scope & 29 & 4.69 & 7 \\
\hline 22 & & Change Orders & 27 & 4.37 & 9 \\
\hline 23 & Changes in & Local Bylaws & 3 & 0.49 & 21 \\
\hline
\end{tabular}




\begin{tabular}{|c|l|l|c|c|c|}
\hline 24 & $\begin{array}{l}\text { Laws of } \\
\text { Regulatory }\end{array}$ & Disapproval of Work & 6 & 0.97 & 18 \\
\cline { 4 - 6 } 25 & \begin{tabular}{l} 
Authorities \\
\cline { 4 - 6 }
\end{tabular} & Other Reasons & 7 & 1.13 & 17 \\
\hline
\end{tabular}

Table 2 Drawing Delay/ Revision Causes and its Frequencies

It can be seen from Table 2 that, the top ranked factors identified are 'Inappropriate assumptions,' 'Ambiguous specifications,' 'Poor information flow' under the categories of "designer's error and omissions and Owner initiated changes." The first two factors, 'Inappropriate assumptions' and 'Ambiguous specifications' forced the designers to make an assumption about the required design information. The design output based on the assumed information (assumption) was passed to the dependent disciplines. The design of the dependent discipline got revised, whenever the assumption got changed. This increased the revisions and delay in the design process. In addition, due to third factor 'poor information flow' the information regarding the changes on the assumption was not communicated to the dependent discipline, which caused the error in the design process. These errors further increased the problem of revision and delay in the deliverables. From this study it is evident that the information management forms the basis for the design process. Hence, the improved interface management is critical to any collaborative design process. The other factors in the above case could have been controlled by administrative management decisions. For example 'less productivity' and 'lack of human resources' and 'suspensions' etc can be solved by instituting motivational training among employees, deploying more resources etc. 


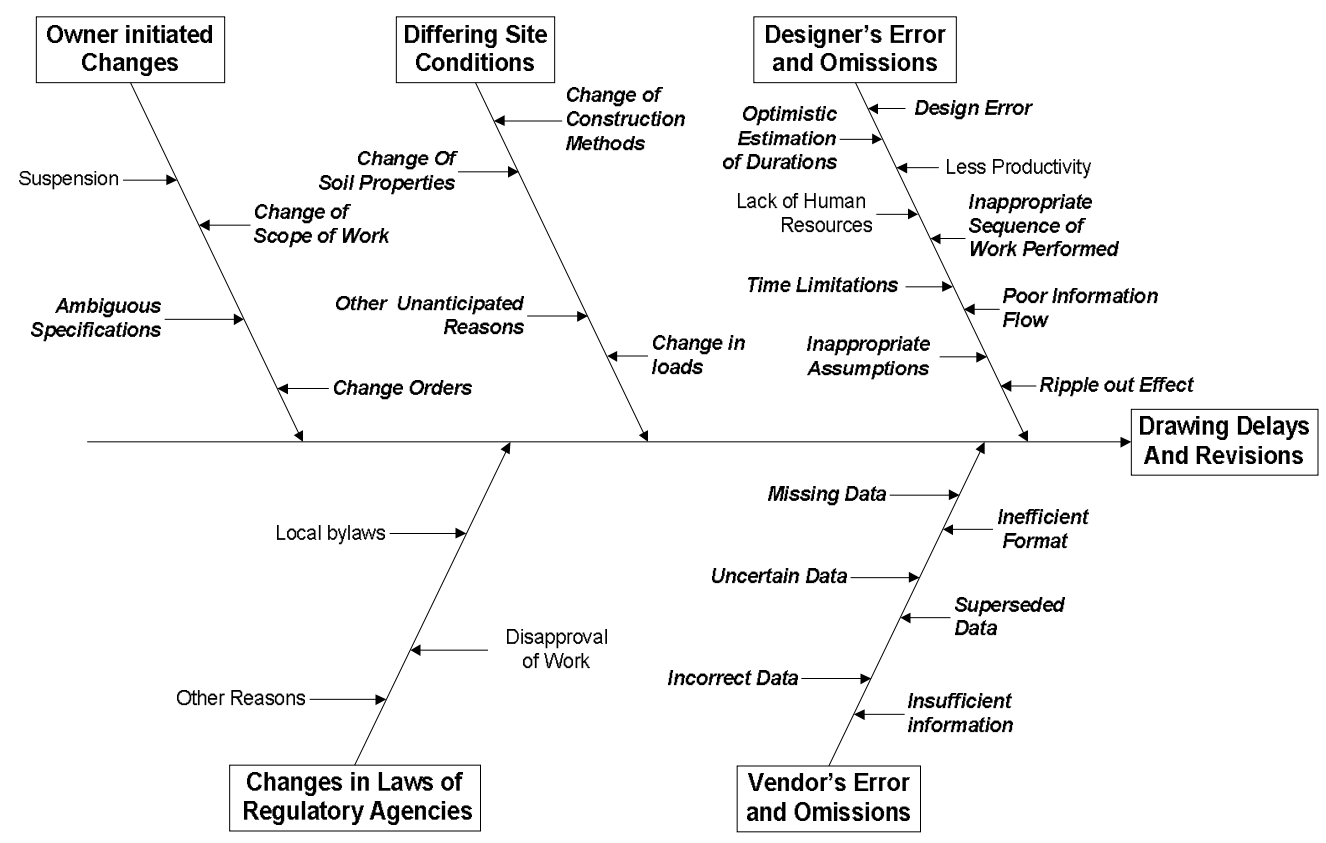

Figure.3 Cause and Effect of Drawing Delays and Revisions

Delay at some point of the design is inevitable on any project but without visibility of the overall interfaces, the knock-on effects of delays and the opportunity to provide timely recovery plans or mitigation measures are lost. Consequently the project staffs have worked in a reactive mode rather than proactive mode, which is compounding the problems. As there were no formal tools to anticipate and avoid these design interface problems, it also exposed the company to significant contractual and commercial risk with respect to obtaining decisions, directions and endorsements from client and demonstrating the true (rather than perceived) effect of any delays and reactionary actions. Utilization of a structured interface methodology in the organizational structure of the company would provide a formal method to anticipate and document the proactive and reactive aspects of the design plan and management. The second cases study gave an opportunity to study the design management process at the conceptual design stage and propose methods to anticipate interfaces and minimize delays and revisions in the design process through lessons from the first case study.

\section{CASES STUDY 2 - AI RPORT DESI GN}

The second case study involves the design of an airport. The project requires the design of a passenger terminal building, airside and landside works of the airport. 
The full airport design consists of more than ten design consultants and the design involves numerous design disciplines such as structural, architectural, electrical, public health engineering, HVAC, mechanical, systems, transportation, baggage handling, interior, airport ground lighting etc. The project's organizational chart for design is shown in figure 4.

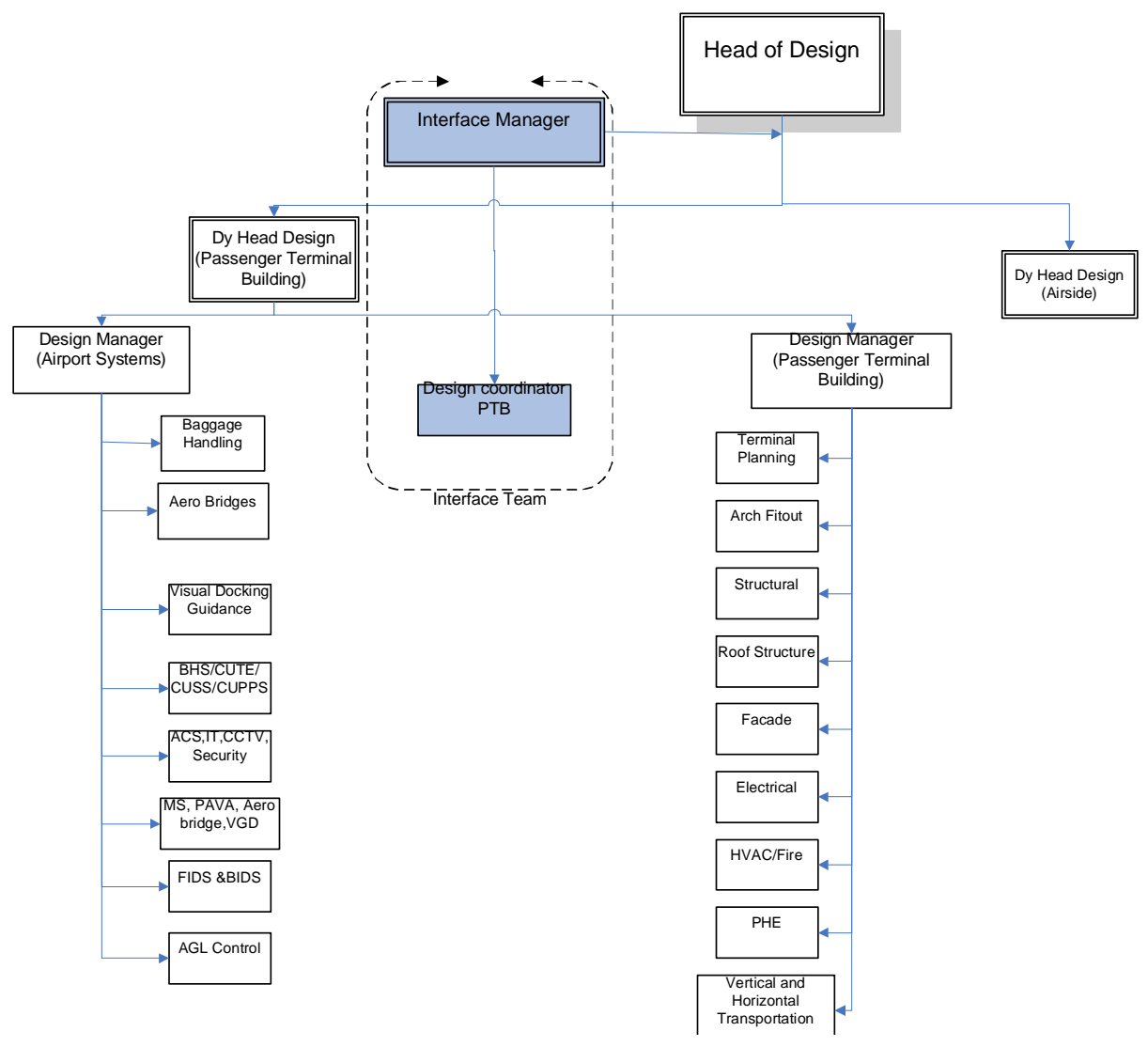

Figure 4 Organizational chart of airport project

As shown in the figure 4, the interface management team was initially consisting of interface manager and design coordinator for each module. The design coordinator is responsible for the coordination issues of the module. The design coordinator ensures and facilitates the coordination between the external agencies and these design disciplines. However, no one is responsible for planning the coordination between the design disciplines. As a result, the design disciplines independently solve the design interface issues as and when it occurs. 
Due to the reactive approach of solving the interface issues many of the design deliverables require multiple revisions. Due to the ripple effect of these revisions there was significant delay in meeting milestones. To resolve these problems in a proactive mode, the top management of the EPC contractor decided to formulate an interface management methodology and formulate the new organizational structure to institute the above said methodology. The following section explains the interface management in design process in general and the details of the proposed new interface management methodology.

\section{I NTERFACE MANAGEMENT I N DESI GN PROCESS}

In the construction design context, a design interface can be defined as:

- Logical design interface which requires information dependency between the disciplines.

- Physical interfaces which require exchange of information as the components share the same space.

To facilitate the integration of the vast array of disciplines which will make up the overall design of the project, a Design Interface Management Plan has to be developed. The issues of design interfaces can be solved in two phases as explained below. The first phase is of a proactive measure to identify interfaces and the second phase is a reactive measure to resolve the interface problems which are not identified in the first step. The first phase is as follows:

- Divide the project in to manageable portions for which the interface documentation is developed.

- Identify the design interfaces between the portions in the early stages

- Progressively develop the interfaces which relate to the interface items such as responsible parties, scheduling, design requirements and design parameters etc.

- Integratethe disciplines for identified design interfaces

- Document, review and revise these interface issues for timely actions

The second phase is as follows: 
- Compare the interfaces in a physical sense by providing an environment where each designer can actively compare their work against all other current designs.

- Identify the existence of design clashes

- Report and resolve in an organized manner

Changes cannot be avoided in the fast track project because of its concurrent nature. However, the delays and impact of a change can be minimized through a change communication mechanism. This mechanism should ensure all design changes are identified, reviewed, approved and communicated to all effected parties and functions. The change management processes will be reviewed as part of the interface management processes.

\section{I NTERFACE MANAGEMENT METHODOLOGY}

The proposed interface methodology has thre major steps: Definition, Capture and Management / Control. In the definition the main project elements are listed out from the work break down structure prepared by the EPC contractor. During the capture stage, all parties involved to the design are required to identify their interfaces with other design parties, vendors and client by a suitable tool through workshop or brainstorming session.

Next, the details of the identified design interfaces (nature and location) are discussed with other interfacing parties and are documented during the interface meetings. As part of the discussions concerning the interface, a realistic date by which the interface designs information is to be available and should be closed, shall also be identified. This date will be adhered to by both the interfacing parties. In the event an interface date cannot be agreed upon, the designer with the most advanced design is required to state the assumed interface agreement, and justify therelevant of the assumptions made with the interfacing parties and proceed with thedesign.

It is also the responsibility of individual design team to prepare, maintain and update the interface record. Each design discipline is also required to prepare a list of major outstanding interface issues which have the potential to affect scope, costs 
or schedule aspects of the design contracts. Major outstanding interface issues may include any of the following a) Lack of information preventing resolution of an interface; b) Failure to agree interface details; c) Proposed additions (or decrease) to scope of works resulting from interface agreements; d) Major changes required to previous interface agreements resulting from revised design direction; and e) Assumptions necessary to proceed to the contracted design schedule.

Each design discipline is required to issue a copy of their interface document, or relevant section thereof, to interfacing design disciplines and external authorities for agreement, information, review and cross-checking as appropriate, on a regular basis. On receipt of the interface record from other disciplines, the responsible design interface coordinator shall review the document for completeness and the technical acceptability of the interface resolutions documented.

The design managers review the list of major outstanding interface issues, if any and initiate any action required to expedite resolution by arranging a joint meeting with interfacing disciplines to discuss the unresolved issue(s). The design manager shall keep the design discipline advised of any change in the status of all such interface issues and obtain the assistance of the design disciplines as appropriate. Any discrepancies, inconsistencies or errors, identified by any reviewer, shall be notified to the originator and the other related parties of the interface.

All the above mentioned process requires resources to implement the same. The interface management team needs to be expanded in the design organization to institute the interface process. The next section explains the modified interface team proposed for the airport project. 


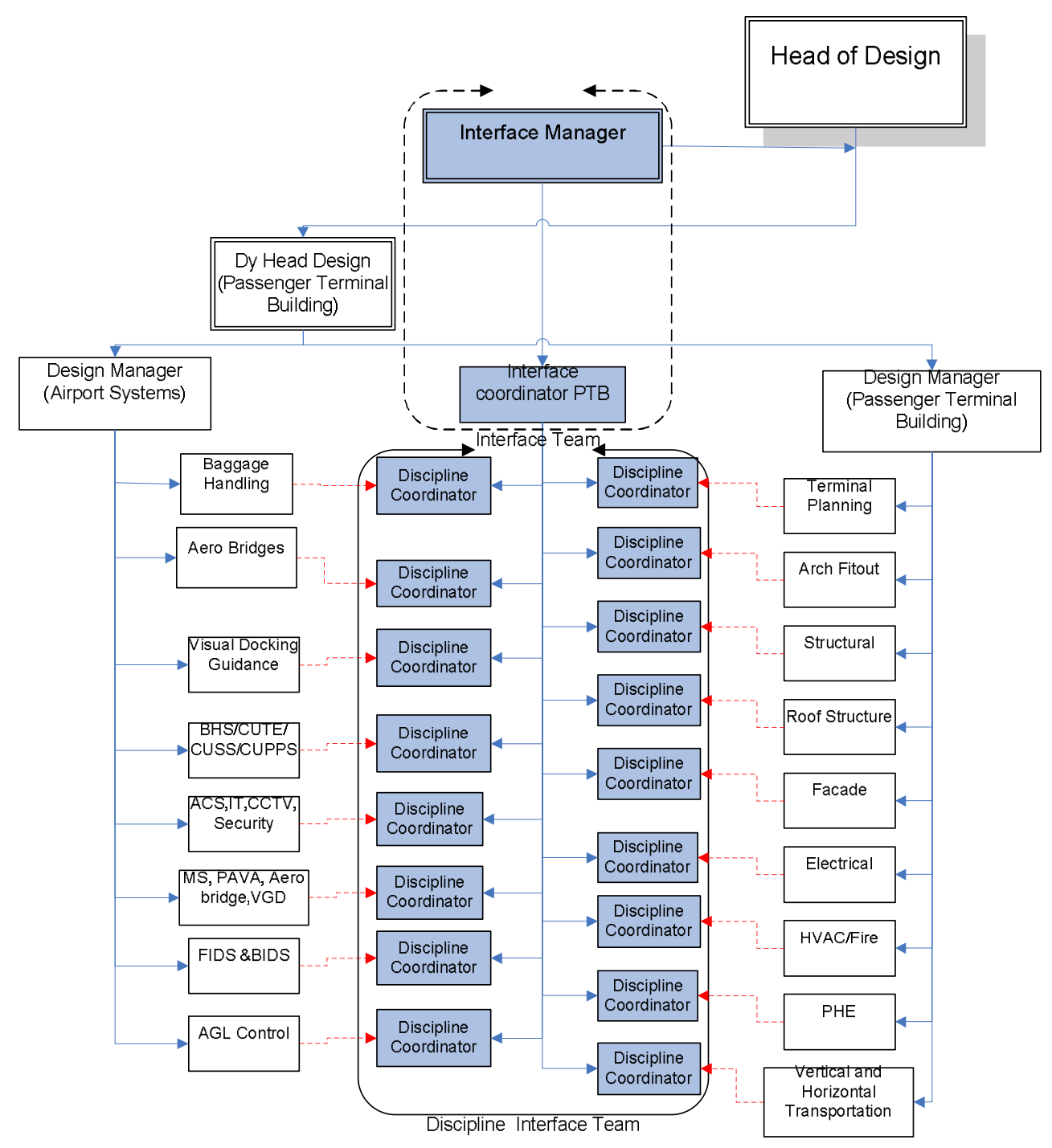

Figure 5 Organization structure of airport project (after modification)

\section{MODI FI ED DESI GN ORGANI ZATI ON}

The modified expanded organizational setup to institute the interface management process of the airport design project is shown in figure 5 . The interface team is headed by the project interface manager, and who is assisted by the interface coordinators for each module in the design process. These coordinators take care of the interface process, like coordinating the interface meetings, solving the issues etc. These coordinators actually act as a facilitator; the actual players in this methodology are the discipline coordinators from each discipline. 
From each team a representative coordinator is deputed to act as an interface coordinator for their discipline. These representative coordinators will do the interface management such as interface identification and solving the interfacing issues etc, in addition to their regular design work. Generally, the team leaders take on the responsibility of the interface coordination for their team, since they are aware of all their design processes.

The discipline coordinators attend the regular scheduled weekly design interface meetings and raise the issues which pertain to their discipline and give inputs on the requirements of other discipline. All the interfacing issues and their corresponding resolutions data needs to be documented and updated. The interface data requirements are finally passed to their designers through discipline leaders for their design.

\section{I MPLEMENTATI ON DI FFI CULTI ES}

It is cumbersome to capture the design interfaces or information dependencies in a complex design process. The network diagram cannot show the details as the number of entities and their dependencies are large on most projects. The Design Structure Matrix (DSM) developed by Steward in 1981 is an effective tool to represent the information flow and understand the relationships among the activities. It has been proved by many researchers that DSM method drastically reduces the design process time of multi disciplinary projects that involves much iteration (Yassine et al. 1999, Eppinger et al. 1994). DSM provides a simple compact and visual representation of a complex system that facilitates novel solutions to decomposition and integration problems (Browning 2001).

The DSM methodology has been applied in various design domains such as automotive industries (Krishnan, 1993), aerospace Engineering (Rogers and Salas, 1999; English et al., 2001) and manufacturing industries (Eppinger et al., 1994; Tang et al., 2000). The applicability of the DSM methodology in construction design has been tested by VTT in Finland (Huovila and Seren, 1998) and Loughborough University (Austin et al., 1999). However limited research has been done in construction industry when compared to other industries. 
This DSM methodology was tried in the airport project for capturing the design interfaces. There are various levels in the design of a project; the author has chosen to capture the drawing interfaces, since the drawings are the output from the design process in any construction project. The project was decomposed in to many small manageable modules and the drawings produced by various disciplines for each module were identified and were listed as rows \& column headings to develop drawing DSM. After the DSM was formulated the design experts from all the involved disciplines were invited for capturing the interfaces of the drawings by populating the developed drawing DSM. Since the airport consists of large number of components and design drawings, the DSM methodology of capturing the drawing interfaces cannot be done manually. The interface capture process during the design interface meeting and the workshop was difficult, because of the larger size matrix (100x100). The designers were finding difficulties in managing the size of the matrix. Finally, it was decided to decompose the project into manageable level of sub components and the DSM is developed for each of these sub components, but the inter-component interfaces were not addressed in the above methodology.

Then the above said methodology was modified to aggregate the DSM based on a color coding concept (Senthlilkumar et.al. 2006). The aggregated DSM was still difficult to manage because of its large and dense nature. The difficulty of the DSM methodology implementation in construction projects lies with decomposition of the project design process and the size of the DSM matrix. The number of design elements (drawings) involved in the construction design process compared to the manufacturing, software and product development domains is more. Hence there is need for better methodology to decompose and integrate various DSM levels.

\section{DI SCUSSI ONS}

The coal handling unit design delay analysis confirms the design delay exists in the project by the designers. The interview of designers listed five categories of high level causes for the design delay. These causes again influenced by many sub factors which also listed in the cause effect diagram. Also the first case study clearly suggests the need for the structured methodology to manage the 
information exchanges in the design of a fast track project. Most of the reasons listed out by the designers for the delay causes, can be avoided by better interface management methodologies. The interface management methodology proposed for the second case study is based on the factors identified from the first case study. The airport design's original organizational structure best suits for the traditional design practices where the project complexity is less. It is also evident from the study that the reactive approach of the designers towards the interface problems causes design delay and revisions. The dedicated interface team proposed in the second case study is one of the solutions for the identification and update of the interface parameters. The inclusion of this in the organizational structure will facilitate the complex interface management process.

From the literature it is appropriate to adopt the DSM methodology to identify and manage the design interfaces. However the usage of the same is limited because of its size constraints when applied to large projects like airport etc. So there should be a modified methodology to adopt the DSM concepts in construction project by incorporating the decomposition and integration of DSMs at various levels of the design process. The difficulties faced during the DSM methodology implementation while capturing the interfaces can be avoided to some extent by automating the process through information technology applications.

From the case studies, it is evident that the design management and information flow management practices are not up to the level at which the modern complex project's demands. The design interface management needs to be addressed in two aspects which include the technical or engineering aspects (appropriate tools and methods) and organizational design \& soft management aspects. The appropriate combination of these may eliminate the design related problems such as delay, revision and poor quality.

\section{REFERENCES}

ARAIN. F, M, PHENG, L, S and ASSAF, I, A. (2006), 'Contractors' Views of the Potential Causes of Inconsistencies between Design and Construction in Saudi Arabia' J ournal of performance of constructed facilities ASCE/February 2006, p 74-83. 
AuStin, S, BALDWIN, A, and NEWTON, A. (1996), 'A Data Flow Model to Plan and Manage the Building Design Process', J ournal of Engineering Design Vol. 7. No 1, 1996. p.3 -25

AUSTIN, S, BALDWIN, A, Li, B and WASKETT, P. (1999) 'Analytical Design Planning Technique: a Model of the Detailed Design Process', Design Studies, Vol 20 No $3 p$ $279-296$.

BROWNING, T.R. (2001), 'Applying the Design Structure Matrix to System Decomposition and Integration Problems: A Review and New Directions', IEEE Transactions in Engineering Management, 48(3), p. 292-306.

DEEPAK Parekh (2007), 'The Report of the Committee on I nfrastructure Financing' Viewed: May 2007 p.3-4, http://www.pppinindia.com/pdf/deepak_parekh_report.pdf.

ENGLISH, K, BLOEBAUM, C L and MILLER, E (2001), 'Development of Multiple Cycle Coupling Suspension in the Optimization of Complex Systems', Structural and Multidisciplinary Optimization, Vol 22 No 4, p.268 - 283.

EPPINGER,S.D, WHITNEY. D. E, SMITH. R. P and GEBALA. D. A (1994), 'A Modelbased Method for Organizing Tasks in Product Development, Research in Engineering Design, 6, p.1-13.

HUOVILA, P and SEREN, K J (1998), 'Customer-Oriented Design Methods for Construction Projects', J ournal of Engineering Design, Vol 9 No 3, p. 225 -238.

KRISHNAN, W (1993), 'Design Process Improvement: Sequencing and Overlapping Activities in Product Development', Ph.D. Dissertation, Department of Mechanical Engineering, Massachusetts Institute of Technology.

ROGERS, J L and SALAS, A O (1999), 'Toward a More Flexible Web-based Framework for Multidisciplinary Design', Advances in Engineering Software, Vol 30, p. 439 - 444.

SENTHILKUMAR V, CHAUDHURI. D. N \& KOSHY Varghese (2006), 'Integrated Hierarchical Systems for Modeling Information Flow in Design Process using Dependency Structure Matrix (DSM), Proceedings of the World IT Conference for Design and Construction, INCITE / ITCSED2006, Vol -I, NewDelhi, India 15-17 November, 2006, p.139-149.

STEWARD, DONALD V 1981, The Design Structure System: A Method for Managing the Design of Complex Systems', IEEE Transactions on Engineering Management, vol. 28, p.71-74.

TANG, D, ZHENG, L, Li, Z, Li, D and ZHANG, S (2000), 'Re-Engineering of the Design Process for Concurrent Engineering', Computers and Industrial Engineering, Vol 38, p. 479-491.

YASSINE. A, FalkeNburg. D \& CHEELST. K (1999), 'Engineering Design Management: An Information Structure Approach". International Journal of Production Research, 37(13), p. 2957 - 2975. 